\title{
Physiological, Anatomical, Psychological and Cultural-Ethnic Aspects of Indian Students Adaptation during Study in Kyrgyzstan Medical Universities
}

\author{
Aziza Seitova1, Georgii Belov1, Zhanibek Muratov1,2, Aizhan Murzalieva1, \\ Zhypargul Abdullaeva ${ }^{*}$ (D), Anara Zhanbaeva ${ }^{2}$, Aliia Zhoroeva1, Imetkul Ismailov1, \\ Alina Pirmatova ${ }^{1}$, Cholpon Orozova ${ }^{1}$, Mariia Murzaeva ${ }^{1}$, Tursunbek Orozbek Uulu ${ }^{1}$ \\ ${ }^{1}$ Department of Pathology, Basic and Clinical Pharmacology, Osh State University, Osh, Kyrgyzstan \\ ${ }^{2}$ Department of Pharmaceutical Disciplines with a Course of Basic and Clinical Pharmacology, Osh State University, Osh, \\ Kyrgyzstan \\ ${ }^{3}$ Department of Anatomy, Histology and Normal Physiology, Osh State University, Osh, Kyrgyzstan \\ Email: *jypar.science@oshsu.kg
}

How to cite this paper: Seitova, A., Belov, G., Muratov, Z., Murzalieva, A., Abdullaeva, Z., Zhanbaeva, A., Zhoroeva, A., Ismailov, I., Pirmatova, A., Orozova, C., Murzaeva, M. and Uulu, T.O. (2021) Physiological, Anatomical, Psychological and Cultural-Ethnic Aspects of Indian Students Adaptation during Study in Kyrgyzstan Medical Universities. Open Journal of Medical Psychology, $10,1-10$.

https://doi.org/10.4236/ojmp.2021.101001

Received: September 24, 2020

Accepted: November 27, 2020

Published: November 30, 2020

Copyright ( 2021 by author(s) and Scientific Research Publishing Inc. This work is licensed under the Creative Commons Attribution International License (CC BY 4.0).

http://creativecommons.org/licenses/by/4.0/ (c) (i) Open Access

\begin{abstract}
This article is investigating the comparative analysis of anatomical, physiological, and psycho-emotional adaptation indicators of 100 male and 100 female first-year students of the international medical faculty in Osh, Kyrgyzstan. Control groups have consisted of 100 male and 100 female local students of the same age, residing in the Osh city and region. Anthropometry is determined by 50 indicators, such as bio-impedance analysis of body composition, functional tests with exercise, and breathe holding. In addition, the girls underwent an assessment of sexual development according to Tyner. The psychological state was assessed using the Lüschers color test and Spielberger's questionnaire. The features of anthropometric indicators for students from India are shown as a shorter length of the body, shoulder, and legs, greater waist coverage, an increase in the thickness of the skin folds of the abdomen, increased fat mass and delayed sexual development, anxiety, frequent and longer colds. Functional tests for breath holding and physical activity revealed less reserve capacity in foreign students. This requires the development of rehabilitation programs for foreign students, starting from the first year.
\end{abstract}

\section{Keywords}

Foreign Students, Adaptation, Component Composition of the Body, Psychological State, Anthropometric Indicators 


\section{Introduction}

The first year in the university seems to be the most critical for adaptation because of the large numbers of possible adjustments [1], characterized by a transition of students into independent life with increased mental activity, responsibility, changing of work mode, food, rest, and sleep, as university students' level of life satisfaction can be predicted by their anxiety and depression level, sex, and socio-economic level [2]. In the case of students who are attending universities in a foreign country, have to contend with novel social and educational organizations, behaviors, and expectations [3]. The adaptation of students to the educational process is accompanied by factors in the psychological health domain, which should jointly promote life satisfaction [4]. Home or host cultural factors influence the ability of students to adapt to individual social contexts and interactions with individuals from different cultural backgrounds related to the reduction of social difficulties [5]. The psychological model of international students' linear intercultural adaptation is associated with language mastery, social interaction, personal development, and academic outcomes [6]. Sharp changes in the rhythm of life do not always go smoothly in a significant part of freshmen, it leads to maladaptive reactions, including depression, a decrease in general reactivity, the manifestation of chronic diseases, and frequent acute respiratory infections [7]. This is especially pronounced among students who came from other regions and countries. Immigrants from Central Asia, studying in Siberia, in large megalopolises Moscow, St. Petersburg, despite the relative commonality of the language and socio-cultural environment, are more difficult to adapt to university studies than local students [8]. The same problems arise for students who came to study in Kyrgyzstan from other countries.

In the last decade, a new direction of the economy has been developing in the Kyrgyz Republic export of education [9]. The total number of foreign students has exceeded 15 thousand and has a tendency to further growth; the vast majority of international students come from India and Pakistan. They have a genetic and physiological adaptation to the conditions of a hot climate [10], which differs significantly from the Kyrgyz people who were adapted to harsh mountain conditions. Indian students are mostly vegetarians. Foreign students also need to adapt to the new social and cultural environment. The adaptation of foreign students to the climatic and geographical conditions of Kyrgyzstan and the psychological burden in a different linguistic and cultural environment has been the focus of individual works [7] [11].

The aim of this work was a comparative description of sexual and physical development, component composition of the body indicators of girls from India and Kyrgyzstan first-year students of Osh State University.

\section{Research Materials}

\subsection{Survey and Psychological Examination}

A survey and psychological examination of freshmen (200 foreign students and 
200 local students) were conducted. Comparative randomized comprehensive anatomical and physiological study of 350 participants adapted within 1 year to the study at medical faculties of Osh State University divided into 4 groups. The groups were randomized by gender, age, time and examination conditions, and lifestyle of all students in the medical faculties of Osh State University. Limitations in this study include students with chronical disorders and age until 25 years old.

The first main group has consisted of 100 freshmen male students who came to study at Osh State University from India and Pakistan. The second main group consisted of 50 first-year female students who arrived to study at Osh State University from India and Pakistan. From 30 groups of the course, survey participants were selected by random selection [12]. The first control group consisted of 100 first-year male students of the Faculty of Medicine, and the residents of Osh city and region. The second control group consisted of 100 first-year female students of the International Faculty of Medicine, and residents of the Osh city and region. The inclusion criteria were: 1) Voluntary consent of participants to a four-time examination; 2) Absence of chronic diseases in participants; 3) Age of participants was from 17 - 24 years.

Cool weather in autumn and cold weather in winter months, an intense academic load, difficulty of preparing usual food cause the frequent development of maladaptive reactions in foreign students. The more frequent development is influenced by initial features of the anatomical and physiological characteristics of students from south and central Asia. When comparing the indicators of adaptive reactions according to characteristics of the cardiovascular system, the prevalence of sympathetic influences on the heart rate in foreign students revealed.

\subsection{Investigation Complex}

1) Students survey performed by using the Lüschers color test claimed that subjects selecting identical color combinations have similar personalities [13]. According to the various research results, the color that surrounds us in daily life has a profound effect on our mood and our behavior [14]. Two concepts were evaluated using the Lüschers color test such as "structure" and "function" of color. Under the "structure" of color meant a stable, common to all people, regardless of race, culture, educational level, gender and age, the value of this color. According to the survey, type of nutrition (vegetarian food, European, Kyrgyz cuisine, fast food, or mixed cuisine), choice of clothes (preserving one's style, switching to clothes that are rational for a given climate), participation in sports games, concerts and other cultural events, communication difficulties, language acquisition, sexual activity, bad habits, alcohol consumption, and sexual life were researched. 2) Evaluation of puberty was carried out on a J. M. Tanner scale [15] [16] [17] with the definition of the secondary sexual characteristic stages of development: development of hair in the armpit (A is axillary), the appearance of pubic hair ( $\mathrm{P}$ is pubis), the shape of the mammary gland ( $\mathrm{Ma}$ is mammae) from 0 to 4 . Three categories for evaluating of menstrual function were determined; 
Me1 means menarche is absent, Me2 means an unsteady menstrual cycle (is a variant of the norm 1 year after the onset of menarche), Me3 is a steady menstrual cycle. The condition of sexual development is usually denoted by the general formula: A, P, Ma, Me, in which the maturation stages of each trait indicated accordingly. 3) Detailed anthropometry test according to 50 indicators (height, sitting height, weight, body mass index, circumference, head, neck, chest, pectoral coverage, waist, hips, lower legs, shoulder, 9 long-length indicators, the thickness of the chest, shoulder, hips, etc.) was performed. 4) Determination of the skin fold (TCS) thickness on the abdomen, lumbar back, hips, and shoulders using a digital electronic caliper KEC-100, with $1 \mathrm{~mm}$ error. 5) Determination of the body component composition by using the bio-impedance analyzer ABC-01 "Medass" with fixing the following parameters: basic metabolism, phase angle, body mass index, body fat mass, nonfat (lean) mass, active cell mass (ACM), percentage of ACM in lean mass, skeletal muscle mass, the percentage of skeletal muscle mass in lean mass, specific basal metabolic rate, total body water, extracellular fluid volume, waist-hip index, and the percentage of body fat. Determination of the component composition of the body in recent years is often used to objectively assess the young people's development dynamics. 6) Spirometry and peak fluorometry measurements performed three times and the greatest result recorded. 7) Systolic blood pressure (BPA) and diastolic (BPD), heart rate (HR), respiration rate $(\mathrm{BH})$, blood oxygenation at rest and during the Martin-Kushelevskaya test were monitored by 20 squats in 30 seconds; monitoring of the blood pressure and heart rate at 1, 3 and 5 minutes after the test. 8) Specific breath tests were performed according to the Shtange's test which is based on the breath holding on inhalation, and the Genchi's tests which are based on the breath-holding on exhalation [18]. The study was carried out during the inhalation phase, where the length of time was measured in which the student, after 3 deep breaths was able to not breathing with closed mouth and nose. Time was set up from the moment of breathing stop to its termination. Genchi's test is characterized by the breath holding on an exhalation. Examined students after complete exhalation and inhalation were exhaled and hold their breaths again. Statistical processing of the obtained data was carried out using the application software "Statistic 6.0". When conducting a statistical analysis, the nature of the distribution of signs on normality was evaluated. The significance of differences in quantitative characteristics having a normal distribution was analyzed using the Student's test in a confidence interval of more than $95 \%$. In the case of abnormal distribution of variation series, the significance of differences was analyzed using the Mann-Whitney test. Differences between the compared values were considered statistically significant at a significance level of $\mathrm{p}<0.05$.

\section{Results and Discussions}

\subsection{Food Preferences}

Questioning showed a sharp difference in food preferences. A vegetarian type of 
food is preferred by $81 \%$ of girls and $79 \%$ of boys in the main group. In the case of local students, no one noted this type of food. Fast food preferred by $15 \%$ of first year females and $14 \%$ of male students from India from the experimental group; $21 \%$ of females and $18 \%$ of male students from the control group. $4 \%$ of first year female and 6\% of male students from India preferred dishes of Kyrgyz cuisine, while less than $1 \%$ of female and male students indicated a preference for mixed European cuisine. European cuisine indicated by $12 \%$ of local female and $9 \%$ of local male students, and the remaining $67 \%$ of local female and $73 \%$ of male students preferred the Kyrgyz cuisine, which is also including Uzbek, Dungan, and Uyghur cousins.

\subsection{Habits}

An assessment of the prevalence of bad habits in the studied groups showed that smoking is not widespread among freshmen, as $12 \%$ of foreign students from India and $10 \%$ of local students were smokers. Smoking girls in the control group were $8 \%$ and among local students, smokers were $14 \%$. According to the literature, data for Russian students who are consuming alcohol were $64 \%$ in examined groups. Among foreign students, $5 \%$ noted the consumption of alcoholic cocktails, $4 \%$ have noted consumption of strong alcoholic drinks like vod$\mathrm{ka}$ and whiskey on holidays; among local youths, $8 \%$ noted strong alcoholic drinks consumption. Weekly consumption of weak alcoholic beverages as beer found only in the control group of local students at $6 \%$. Analysis of the daily diet showed an excessive consumption of carbohydrates and a lack of protein food in foreign female and male students. The food is more balanced among local students, especially in the indigenous people of Osh.

\subsection{Psychological Indicators}

A comparison of the adaptive reaction indicators according to the characteristics of the cardiovascular system revealed the prevalence of sympathetic influences on the heart rhythm. Largely, the activation of the sympathetic part of the autonomic nervous system and its predominance over the parasympathetic characterized in first year males from India. The stress index of foreign students was higher than the physiological norm, therefore, the vegetative tone corresponded to hypersympathicotonia, which is evidence of overstrain in regulatory systems. The psychological analysis revealed significant differences as shown in Figure 1.

The rate of negativity was significantly lower among the local female and male students $(17 \%-21 \%)$, versus ( $46 \%-50 \%)$ among foreign students. Significant differences are also characterized two or more times by indicators such as "irritation", "resentment", and the "hostility index". In terms of "physical aggressiveness", "indirect aggressiveness", "suspiciousness" no significant differences were found. Assessment of mental comfort in most of freshmen students showed insufficient mental comfort. $13 \%$ of students from the control group and $23 \%$ of students from experimental groups were in a state of mental discomfort. Such 


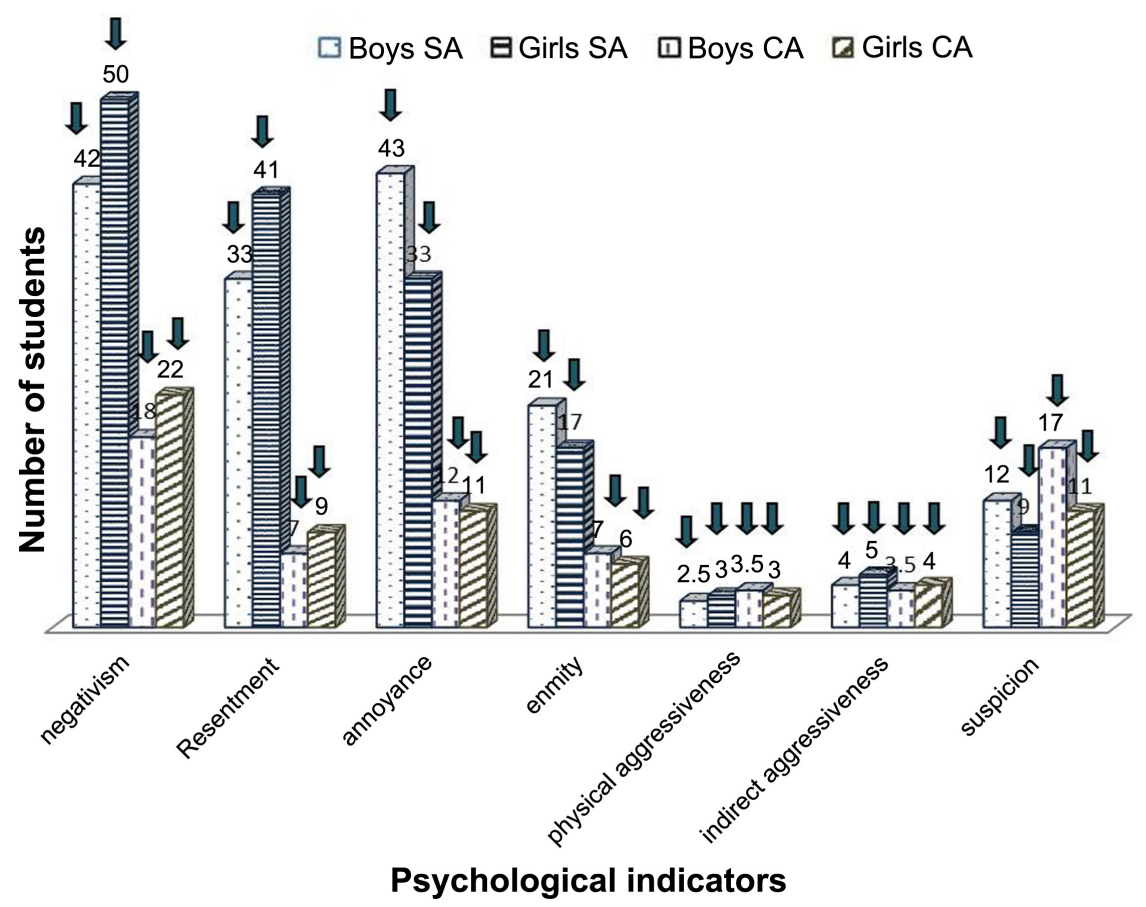

Figure 1. Psychological indicators in male and female students of the main and control groups. Note: the arrow is a significant difference within the control group, $\mathrm{p}<0.05$.

students are characterized by increased fatigue, weakened memory and attention, difficulties in assimilating material and attempts to concentrate, and temper.

\subsection{Anthropometric Indicators}

Initial indicators of physical development influenced the processes of student life adaptation. Out of 50 anthropometric indicators, a reliable difference was identified by 6 indicators as shown in Figure 2. Conducted anthropometric studies [19] have revealed significant differences in student's height, sitting height, shoulder length, leg length, and chest span sizes, which were lower in the main groups. Waist coverage [20] for females from SA was significantly greater [21]. The thickness of the skin fold localization in boys was less than in girls, which is consistent with the previous data. On the anterior abdominal wall, the skinfold thickness was significantly larger for students from South Asia by 12 and $17 \mathrm{~mm}$, respectively, compared with the control groups [22]. On the anterior of the abdominal wall, it was significantly greater among students from South Asia compared with the control groups. The fat mass in young men of the main group in kilograms was exceeded comparing to the control group at $70.5 \%$. Similarly, $70.9 \%$ of the fat mass expressed as a percentage of the total mass, the amount of which was greater in the main group students. Accordingly, the lean muscle mass in the main group students was significantly lower compared to the students from the control group ( $\mathrm{p}<0.05)$. The active muscle mass and musculoskeletal mass were smaller in the main group students, both in kilograms and 


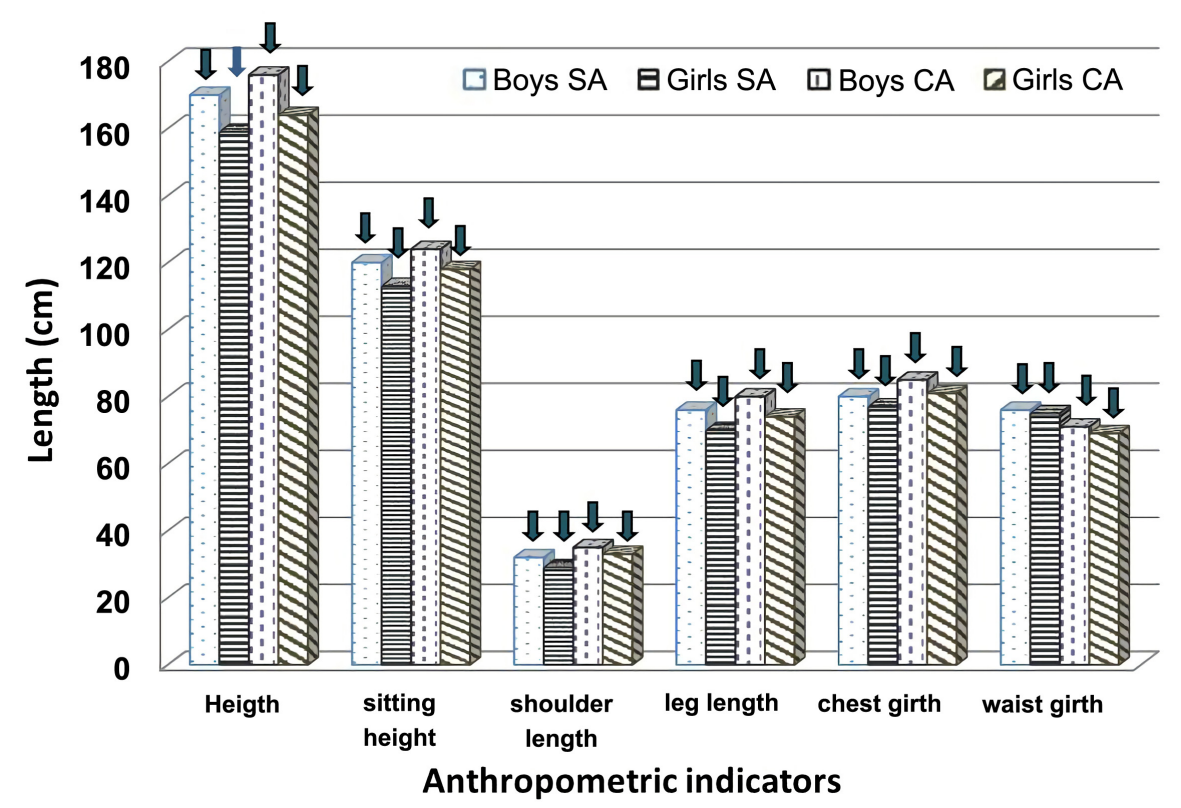

Figure 2. Anthropometric indicators of male and female students from Southern Asia (SA) and Central Asia (CA), respectively. Note: arrows are the different criteria within the control group $\mathrm{p}<0.05$.

in percentage values. Also, young men from India were characterized by a significantly lower specific basal metabolic rate $(\mathrm{p}<0.05)$.

The anthropometric studies revealed significant differences in height, sitting height, shoulder length, leg length, and chest size, which were $8 \%-15 \%$ lower in the main groups of boys and girls.

The female students of the main and control groups, as compared to the first year male students, were distinguished by a greater fat mass, expressed both in kilograms ( $\mathrm{kg}$ ) and percentage (\%) values and a lower musculoskeletal mass, with less intense specific basal metabolism. The female student groups were differed from each other by fat mass, lean (lean) mass, skeletal mass, and specific basal metabolism. Local female students had higher specific basal metabolism, musculoskeletal mass, and correspondingly less fat mass ( $\mathrm{p}<0.05)$. A survey of students in the control group revealed that they had Menarche at $12.6 \pm 0.6$ years of age. In the main group, Menarche started later at $13.8 \pm 0.6$ years old, and the phase of the unsteady menstrual cycle stretched for 1.5 years or more, which corresponds to the information available in the scientific literature [23]. The form of the mammary gland is considered as one of the criteria for the biological age of women. As it can be seen from Table 1, only $43 \%$ of the girls of the main group had an adult breast shape, and $22 \%$ had a Tanner shape of Ma2 (a large paranasal circle, together with a nipple forms a cone, the gland protrudes slightly above the skin level).

In the control group, the $\mathrm{MA}_{2}$ breast shape did not occur at all, $63 \%$ of local freshmen had an adult $\mathrm{MA}_{4}$ breast shape. Comparative functional anthropogenic studies of male and female students the main and control groups revealed higher 
Table 1. Tanner's sexual development indicators for girls from India and Kyrgyzstan.

\begin{tabular}{ccccc}
\hline Group & $\mathbf{A}$ & $\mathbf{P}$ & $\mathbf{M a}$ & $\mathbf{M e}$ \\
\hline \multirow{3}{*}{ Basic } & $\mathrm{A}_{2}-6.6 \%$ & $\mathrm{P}_{2}-6.6 \%$ & $\mathrm{Ma}_{2}-22 \%$ & $\mathrm{Me}_{1}-0 \%$ \\
& $\mathrm{~A}_{3}-53.4 \%$ & $\mathrm{P}_{3}-49.4 \%$ & $\mathrm{Ma}_{3}-35 \%$ & $\mathrm{Me}_{2}-15 \%$ \\
& $\mathrm{~A}_{4}-40 \%$ & $\mathrm{P}_{4}-44 \%$ & $\mathrm{Ma}_{4}-43 \%$ & $\mathrm{Me}_{3}-85 \%$ \\
& & & & \\
Control & $\mathrm{A}_{2}-0 \%$ & $\mathrm{P}_{2}-8 \%$ & $\mathrm{Ma}_{2}-0 \%$ & $\mathrm{Me}_{1}-0 \%$ \\
& $\mathrm{~A}_{3}-45 \%$ & $\mathrm{P}_{3}-40 \%$ & $\mathrm{Ma}_{3}-37 \%$ & $\mathrm{Me}_{2}-0 \%$ \\
& $\mathrm{~A}_{4}-5 \%$ & $\mathrm{P}_{4}-52 \%$ & $\mathrm{Ma}_{4}-63 \%$ & $\mathrm{Me}_{3}-100 \%$ \\
\hline
\end{tabular}

systolic and diastolic blood pressure in students from India. They also noted significantly higher heart rates. This difference in blood pressure and heart rate persisted in all seasons. Similar changes in autonomic functions in the form of increased blood pressure and heart rate were noted in first year students who came from humid and sub-tropical countries. Foreign students have less functional reserves, which is leads to more frequent development of maladaptive reactions, as well as more frequent detection of acute respiratory and intestinal infections in their first year.

\section{Conclusions}

Differences in indicators of sexual and physical development, as well as the component composition of the body in healthy female and male students from India and Kyrgyzstan, which had both genetic and ethnic backgrounds, have been studied and revealed. We have monitored functional indicators in Indian and local male and female students by stress tests. The Shtange's breathing test results with breath-holding on maximum inhalation in males and females from Kyrgyzstan (Central Asia) were significantly higher $(p<0.05)$ than in students from India (South Asia). Genchi's test with breath holding on exhalation is significantly higher in young males from Kyrgyzstan.

These identified features of students from India should be taken into account for the implementation of developing programs aimed to improve the processes of their adaptation to study and life in the conditions of Kyrgyzstan.

\section{Ethical Statement}

All procedures performed in studies involving human participants were following the ethical standards of the institutional and/or national research committee and with the 1964 Helsinki declaration and its later amendments or comparable ethical standards.

\section{Conflicts of Interest}

Authors declare that the research conducted in the absence of any commercial or financial relationships that could be construed as a potential conflict of interest.

\section{References}

[1] Clinciu, A.I. (2013) Adaptation and Stress for the First Year University Students. 
Procedia-Social and Behavioral Sciences, 78, 718-722. https://doi.org/10.1016/j.sbspro.2013.04.382

[2] Zhou, Y.F., Jindal-Snape, D., Topping, K. and Todman, J. (2008) Theoretical Models of Culture Shock and Adaptation in International Students in Higher Education. Studies in Higher Education, 33, 63-75. https://doi.org/10.1080/03075070701794833

[3] Serin, N.B., Serin, O. and Özbaş, F.L. (2010) Predicting University Students' Life Satisfaction by Their Anxiety and Depression Level. Procedia-Social and Behavioral Sciences, 9, 579-582. https://doi.org/10.1016/j.sbspro.2010.12.200

[4] Zhou, M. and Lin, W.P. (2016) Adaptability and Life Satisfaction: The Moderating Role of Social Support. Frontiers in Psychology, 7, 1134.

https://doi.org/10.3389/fpsyg.2016.01134

[5] Chen, Y.Y., Su, J., Re, Z.R and Huo, Y.Q. (2019) Optimism and Mental Health of Minority Students: Moderating Effects of Cultural Adaptability. Frontiers in Psychology, 10, 2545. https://doi.org/10.3389/fpsyg.2019.02545

[6] Gu, Q., Schweisfurth, M. and Day, C. (2010) Learning and Growing in a 'Foreign' Context: Intercultural Experiences of International Students. Compare, 40, 7-23. https://doi.org/10.1080/03057920903115983

[7] Chonkoeva, A. and Chyngyshpaev, D.S. (2014) Comparative Evaluation of Foreign Students' Psychophysiological Adaptation to Vocational Training Conditions. Medicine of Kyrgyzstan, 1, 84-87.

[8] Pyrkova, K.V. (2016) Features of International Students' Adaptation (on the Basis of a Russian Higher Education Institution). International Electronic Journal of Mathematics Education, 11, 611-621.

[9] Schatz, M. (2015) Toward One of the Leading Education-Based Economies? Investigating Aims, Strategies, and Practices of Finland's Education Export Landscape. Journal of Studies in International Education, 19, 327-340. https://doi.org/10.1177/1028315315572897

[10] Singh, T., Siderius, C. and Van der Velde, Y. (2018) When Do Indians Feel Hot? Internet Searches Indicate Seasonality Suppresses Adaptation to Heat. Environmental Research Letters, 13, Article ID: 054009. https://doi.org/10.1088/1748-9326/aaba82

[11] Dzhumalieva, A.A., Asanbaev, A.M. and Khan, M. (2013) Adaptation of Foreign Students in the International Higher School of Medicine of Kyrgyzstan. Medicine of Kyrgyzstan, 7, 15-17.

[12] Li, D.Y., Sinha, B.K. and Perron, F. (1999) Random Selection in Ranked Set Sampling and Its Applications. Journal of Statistical Planning and Inference, 76, 185-201. https://doi.org/10.1016/S0378-3758(98)00136-0

[13] Picco, R.D. and Dzindolet, M.T. (1994) Examining the Lüscher Color Test. Perceptual and Motor Skills, 79, 1555-1558. https://doi.org/10.2466/pms.1994.79.3f.1555

[14] Kurt, S. and Osueke, K.K. (2014) The Effects of Color on the Moods of College Students. SAGE Open, 4, 1-12. https://doi.org/10.1177/2158244014525423

[15] Cole, T.J., Pan, H. and Butler, G.E. (2014) A Mixed Effects Model to Estimate Timing and Intensity of Pubertal Growth from Height and Secondary Sexual Characteristics. Annals of Human Biology, 41, 76-83.

https://doi.org/10.3109/03014460.2013.856472

[16] Herman-Giddens, M.E., Steffes, J., Harris, D., Slora, E., Hussey, M., Dowshen, S.A. and Reiter, E.O. (2012) Secondary Sexual Characteristics in Boys: Data from the Pediatric Research in Office Settings Network. Pediatrics, 130, e1058-e1068. 
https://doi.org/10.1542/peds.2011-3291

[17] Carskadon, M.A. and Acebo, C. (1993) A Self-Administered Rating Scale for Pubertal Development. Journal of Adolescent Health, 14, 190-195.

https://doi.org/10.1016/1054-139X(93)90004-9

[18] Romanchyk, A. and Dolgier, E. (2017) Effects of Long-Term Training Experience of Aerobic Exercises on Middle-Aged Women. Journal of Physical Education and Sport, 17, 680-687.

[19] Kęska, A., Lutosławska, G., Mazurek, K., Czajkowska, A., Tkaczyk, J., Iwańska, D. and Kȩska, A. (2018) Changes in Anthropometry and Selected Metabolic Parameters in Young Men during Their First Year of Study at a University of Physical Education. American Journal of Men's Health, 12, 463-471.

https://doi.org/10.1177/1557988317743151

[20] Midha, T., Krishna, V., Nath, B., Kumari, R., Rao, Y.K., Pandey, U. and Kaur, S. (2014) Cut-Off of Body Mass Index and Waist Circumference to Predict Hypertension in Indian Adults. World Journal of Clinical Cases, 2, 272-278.

https://doi.org/10.12998/wjcc.v2.i7.272

[21] Dilip, M.S. and Anand, U.S. (2017) Waist-to-Height Ratio in Indian Women: Comparison with Traditional Indices of Obesity, Association with Inflammatory Biomarkers and Lipid Profile. American Journal of Men's Health, 29, 411-415. https://doi.org/10.1177/1010539517717509

[22] Jürimäe, T., Sudi, K., Jürimäe, J., Payerl, D., Möller, R. and Tafeit, E. (2005) Validity of Optical Device Lipometer and Bioelectric Impedance Analysis for Body Fat Assessment in Men and Women. Collegium Antropologicum, 29, 499-502.

[23] Nasirdinova, Z.M., Isakova, Z.K., Jetigenova, S.A. and Musuraliev, M.S. (2014) The Formation of Menstrual Function in the Residents of the Mountains of Kyrgyzstan, Yemen and Nepal. Bulletin of the KSMA Named after I.K. Akhunbaeva, 1, 33-36. 